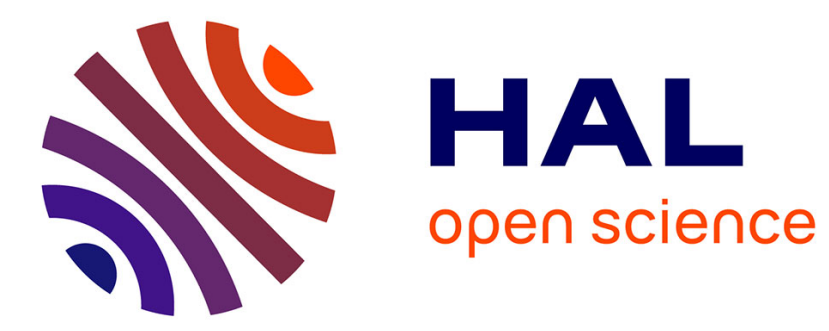

\title{
Fragmentation of small carbon clusters, a review
}

K. Béroff, M. Chabot, F. Mezdari, G. Martinet, T. Tuna, P. Désesquelles, Arnaud Le Padellec, M. Barat

\section{To cite this version:}

K. Béroff, M. Chabot, F. Mezdari, G. Martinet, T. Tuna, et al.. Fragmentation of small carbon clusters, a review. The Seventh International Symposium on Swift Heavy Ions in Matter, Jun 2008, Lyon, France. hal-00278740

\section{HAL Id: hal-00278740 \\ https://hal.science/hal-00278740}

Submitted on 21 Jul 2008

HAL is a multi-disciplinary open access archive for the deposit and dissemination of scientific research documents, whether they are published or not. The documents may come from teaching and research institutions in France or abroad, or from public or private research centers.
L'archive ouverte pluridisciplinaire HAL, est destinée au dépôt et à la diffusion de documents scientifiques de niveau recherche, publiés ou non, émanant des établissements d'enseignement et de recherche français ou étrangers, des laboratoires publics ou privés. 


\section{FRAGMENTATION OF SMALL CARBON CLUSTERS, A REVIEW}

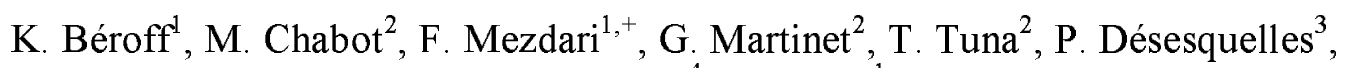
A.LePadellec ${ }^{4}$, M. Barat ${ }^{1}$

1 : Laboratoire des Collisions Atomiques et Moléculaires, CNRS and Université Paris-Sud, bâtiment 351, 91405 Orsay Cedex, France

2 :Institut de Physique Nucléaire, CNRS-IN2P3 and Université Paris-Sud, 91405 Orsay Cedex, France

3 :Centre de Spectrométrie Nucléaire et Spectrométrie de Masse, Université Paris-Sud and CNRS-IN2P3, bâtiment 104, 91405 Orsay Cedex, France

4 :Institut de Recherche sur les Systèmes Atomiques et Moléculaires Complexes, Université Paul Sabatier and CNRS, bâtiment 3R1B4, 31062 Toulouse Cedex 9, France

+ present address : Institut des Nanosciences de Paris, Université Paris 6 and CNRS, Campus Boucicaut, 140 rue de Lourmel, 75015 Paris Cedex, France

PACS: $36-40 \mathrm{Qv} ; 36-40 \mathrm{Wa}$

\section{Abstract:}

An overview of the works devoted to fragmentation of small carbon clusters is given in a first part. Fragmentation of swift neutral and (multi) charged carbon clusters studied with the AGAT spectrometer is presented and discussed in a second part.

\section{I-Introduction}

Carbon clusters are covalent clusters, particularly robust. Typically, $6 \mathrm{eV}$ is needed to break a bond between carbon atoms. Because of that, they are formed and observed in hot media (plasmas, flames) and play a large role in combustion processes. They have also been detected in comets and planetary environments, interstellar and circumstellar medium. In these astrophysical environments, a rich carbon chemistry is operating, in which fragmentation plays a large role. Main contributing processes to the evolution of chemical species are 
dissociative recombination between electrons and cations, ion-neutral and neutral-neutral reactions, photodissociation and cosmic-ray induced excitation and ionization. The relative importance of these processes depends on the considered medium. Still, the way electronic or vibrational energy deposited in the polyatomic system will relax is fundamental. Presently there is a lack of fragmentation data in astrochemical codes for most of the introduced species, including carbon clusters. Indeed, although numerous works have been devoted to carbon clusters [1-3], they mostly rely on spectroscopic studies and very few on fragmentation, especially for neutral and multicharged clusters

In this contribution, we will discuss main features of the present status of knowledge of fragmentation of carbon clusters, restricting to the smallest species $(n<20)$. In section II, we will present an overview of experimental and theoretical works on carbon clusters fragmentation. Then in section III, we will present the AGAT spectrometer devoted to the fragmentation spectroscopy which is installed at the Tandem accelerator in Orsay (France). This spectrometer is a high-velocity tool, ie, operating with swift projectiles. The fragmentation of swift clusters, excited in collision with atoms, has then been studied. In section IV, we will discuss energy deposits occurring in these collisions, which are major entries for the fragmentation analysis. Some fragmentation results and analysis will be presented in section $\mathrm{V}$, for neutral carbon clusters, monocharged carbon clusters and multiplycharged carbon clusters. Summary and perspectives will shortly be presented to conclude.

\section{II-Review of experiments and theories on small carbon clusters}

In this overview, both prompt and delay fragmentation associated to various "detection time windows" and corresponding to various internal energies of the clusters will be discussed 
Cationic carbon clusters are by far the most studied species. This is because experimentally the identification of ionic fragments is easy, using electric or magnetic fields. In pioneering works, Geusic et al $[4,5]$ studied the photodissociation of $\mathrm{C}_{\mathrm{n}}{ }^{+}$clusters $(\mathrm{n}=3-20)$ following one and two-photon absorption of $3.5 \mathrm{eV}$ and $5 \mathrm{eV}$, detecting the ionic fragment alone by TOF measurement. They showed that $\mathrm{C}_{3}$ emission from $\mathrm{C}_{\mathrm{n}}^{+}$(giving rise then to a $\mathrm{C}_{\mathrm{n}-3}{ }^{+}$ionic fragment) was the dominant channel. We will present some of their results in section V. Later on, the same kind of apparatus was used by Bouyer et al [6] for studying the kinetics of dissociation of larger $\mathrm{C}_{\mathrm{n}}^{+}(\mathrm{n}=19-29)$ species. Metastable dissociation $(\mu \mathrm{s})$ of $\mathrm{C}_{\mathrm{n}}^{+}$clusters ( $\mathrm{n}=5-60)$ was studied by Radi et al [7] also quite a time ago. This long lived dissociation is associated to small energy deposits so that information on lowest energy dissociation channels is accessible by this method. Radi et al showed that the lowest energy channel involves $\mathrm{C}_{3}$ emission for $\mathrm{n}<20, C_{5}$ emission for $\mathrm{n}<30$ and $C_{2}$ emission for $\mathrm{n}>30$. Fragmentation of $\mathrm{C}_{\mathrm{n}}^{+}$ clusters following low energy collisions (CID) with gases was investigated by various authors in the $\mathrm{keV}[8]$ and $\mathrm{eV}[9,10]$ collision energy regime (and $\mathrm{n}=2-19)$. We will discuss results of Lifshitz et al [8] also in section $\mathrm{V}$.

Fragmentation of neutral clusters is much less documented. In order to detect neutral fragments, neutral clusters must have been previously accelerated. Choi et al [11] accelerated at $\mathrm{keV}$ energy anionic $\mathrm{C}_{\mathrm{n}}(\mathrm{n}=4-6)$ that they photodetached with a first laser before studying the photodissociation of neutral $\mathrm{C}_{\mathrm{n}}$ with a second laser. The experimental method only allowed two-fragments dissociation to be studied. Kinetic energy distributions of both fragments were recorded in coincidence for main channels $\left(\mathrm{C}_{3} / \mathrm{C}, \mathrm{C}_{3} / \mathrm{C}_{2}, \mathrm{C}_{4} / \mathrm{C}, \mathrm{C}_{3} / \mathrm{C}_{3}\right)$ and were compared favourably to results of the statistical PST (Phase Space) theory. This demonstrated an efficient conversion of the electronic excitation (laser) into vibrational 
excitation in the electronic ground state (as assumed within PST). Fragmentation of $\mathrm{C}_{n}$ clusters $(n=3-4)$ following dissociative recombination (DR) between merged electrons and $\mathrm{C}_{\mathrm{n}}^{+}$cations was studied recently nearby the Astrid storage ring [12]. In this paper the competition between two relaxation channels (IR emission and dissociation) was also discussed based on theoretical estimates.

Fragmentation of multiply charged carbon clusters is almost unknown. Some indirect information was obtained on multicharged fragments of multicharged $C_{60}$ [13] but no extensive study existed until our measurements (see section V). The fragmentation of anionic carbon clusters, that we will not discuss in this paper, is also rather unexplored. Crude experimental information on fragmentation [14] allowed to conclude to preferential $\mathrm{C}_{3}$ emission, in accordance with dissociation energy calculations [15]. An interesting topics relates to the competition between detachment [16] and dissociation, poorly investigated.

\section{$b$ - theories}

Fragmentation theories all rely on robust structure calculations. First post Hartree Fock calculations on $\mathrm{C}_{\mathrm{n}}$ and $\mathrm{C}_{\mathrm{n}}^{+}$clusters were carried out by Raghavachari et al $(\mathrm{n}=2-10)$ [17]. In this study, basic results were established, amongst them the highest stability of odd clusters as compared to even clusters (for neutral and, in a lesser extent, for cations). Indeed, in linear odd neutral clusters, electronic shells are closed although this is not possible for linear even clusters. In this last case, cyclic isomers exist that are very close in energy. There is still work on the separation between isomers of even clusters (in particular $\mathrm{C}_{4}{ }^{(+)}, \mathrm{C}_{6}{ }^{(+)}$) and the uncertainty on measured ionization energies resulting from that $[18,19]$. An extensive work within DFT (Density functional theory) and CCSDT (Coupled Cluster theory) has been carried out by the group of Martin J.M.L et al [20] on neutral $C_{n}(n=2-18)$. The same kind of calculations was carried out by the group of Martin F., Alcami et al on $C_{n}, C_{n}^{+}[21], C_{n}^{++}$ 
[22] and $\mathrm{C}_{\mathrm{n}}^{+++}[23]$ species $(\mathrm{n}=1-10 / 12)$. On the other hand, semi-empirical models were developed for neutral and charged clusters $(n \leq 14,20,60)$ for dynamical application purposes [24]. In addition to these studies in electronic ground states, calculations on electronic excited states of $\mathrm{C}_{\mathrm{n}}$ and $\mathrm{C}_{\mathrm{n}}^{+}$were carried out by various groups [25],[26]. Also, ab initio calculations of the ionization spectrum of $\mathrm{C}_{\mathrm{n}}$ clusters were performed by Ohno et al [27] and Deleuze et al $[28,29]$ for $n \leq 13$. This ionization spectrum provides the excitation energy distribution of ionised $\mathrm{C}_{\mathrm{n}}^{+}$, as will be seen in section IV.

Most theoretical studies concerning the fragmentation of carbon clusters have been conducted within a statistical framework. In this one, it is assumed that the energy of the cluster is concentrated on the electronic ground state and is shared between vibrational and rotational excitation. Amongst statistical approaches the Phase Space Theory (PST) was used for extracting, from metastable dissociation of $\mathrm{C}_{\mathrm{n}}^{+}$, dissociation energies in these species [30]. The simulation of kinetic energy distributions of fragments in the photodissociation of $C_{n}$ clusters was obtained in a satisfactory way using the PST theory by Choi et al [11]. The importance of considering all possible isomers for prediction of dissociation branching ratios of $\mathrm{C}_{4}$ and $\mathrm{C}_{5}$ was studied theoretically again with the PST theory by Calvo and Parneix [31]. Nevertheless, the most complete statistical fragmentation study of neutral carbon clusters was carried out by Diaz-Tendero et al [32] within the Weisskopf and MMMC (Microcanocical Metropolis Monte Carlo) models through many aspects: consideration of all possible dissociative channels, introduction of a large number of isomers, inclusion of rotational energy, examination of kinetics. The MMMC model has been compared to experiment (section V-a).

Another approach of fragmentation is furnished by molecular dynamics. This approach usually requires, for practical application, a rapid fragmentation (100 fs) and may then cause 
problems when the dissociation is not fast enough. But it may be well adapted for dissociation occurring in multicharged species, as planned to be done for the fragmentation of $\mathrm{C}_{\mathrm{n}}{ }^{\mathrm{q}}$ clusters (see section V).

\section{III-The AGAT fragmentation spectrometer}

A schematic view of the spectrometer is shown in figure 1 . After collision of a swift $\mathrm{C}_{\mathrm{n}}^{+}$ projectile with an atom in the gaseous jet, fragments are deflected, according to their charge over mass ratios, by an intense electric field and impinge on solid-state surface barrier detectors which provide transient currents. The analysis of the current shape allows to resolve the number and the mass of each fragment impinging on the detector [33]. The resolving power increases with the fragments velocities, as illustrated in figure 2 . The seven detectors, operating in coincidence, cover the whole solid angle. For each event, the charge state of the cluster after the collision is reconstructed and the associated fragmentation separately recorded. Fragmentation of neutral $\mathrm{C}_{\mathrm{n}}$ clusters occurs after neutralization (electron capture) of $\mathrm{C}_{\mathrm{n}}^{+}$in the collision. Fragmentation of $\mathrm{C}_{\mathrm{n}}^{+}$clusters is due to dissociative electronic excitation in the collision. Fragmentation of $\mathrm{C}_{n}^{++}$(respectively $\mathrm{C}_{n}^{+++}, \mathrm{C}_{n}^{++++}$) is due to single ionization (respectively double ionization and triple ionization) in the collision. Results presented below are obtained with collision with helium atoms and projectile velocity of 2.6 a.u (2MeV/carbon atom).

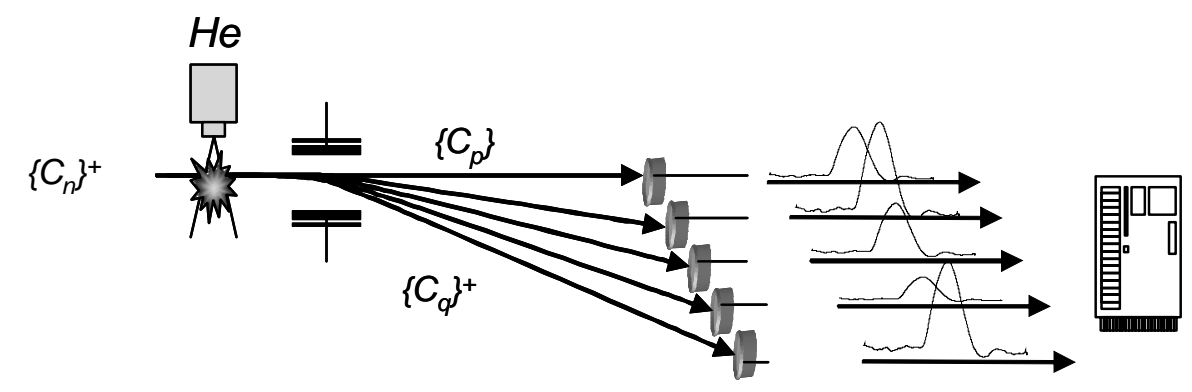

Figure 1: 

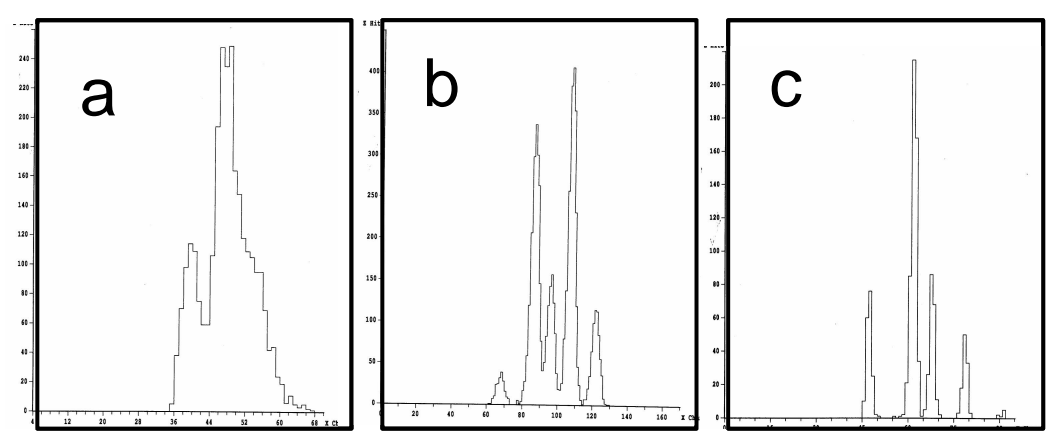

\section{Figure 2:}

\section{IV-Energy deposits in clusters excited in high velocity collisions}

Energy deposits are not measured in the experiment. An experimental estimate may be extracted from the fragmentation multiplicity distribution (ie distribution of the number of emitted fragments) as will be discussed below. Another possibility is to calculate the energy deposit taking place during the collision. This is what we did for the excitation and ionization processes, using a simple collisional modelling in which clusters are assumed to be made of independent atoms (IAE model). The method has been described for excitation [34] and it was found that the energy deposit, centered around $18 \mathrm{eV}$, was not changing much with the cluster size.

The internal energy of ionised clusters comes (mainly) from the fact that ejection of inner valence electrons takes place during the collision. The energy distribution due to single ionization $\mathrm{f}\left(\mathrm{E}^{\mathrm{SI}}{ }_{\text {ion }}\right)$ is expressed as :

$$
f\left(E^{S I}{ }_{i o n}\right)=\sum_{\alpha} \delta\left(E^{S I}{ }_{i o n}-E_{\alpha}\right) \sum_{i} f_{i}^{(\alpha)}\left(\frac{\sigma(i)}{\sigma_{\text {tot }}}\right)
$$

Where $\mathrm{E}_{\alpha}$ represents the energy of level $\alpha$ in the ionised cluster, IP is the ionization potential of the parent (neutral) cluster, $f_{i}^{(\alpha)}$ the pole strength which provides the probability of 
populating level $\alpha$ by ejecting an electron of the ith molecular orbital, $\sigma(i)$ the cross section for ionising this molecular orbital $\mathrm{i}$ and $\sigma_{\mathrm{tot}}$ the total single ionisation cross section. This formula resembles expressions used in photoionisation of molecules [35]. We used $\mathrm{E}_{\alpha}$ and $\mathrm{f}_{\mathrm{i}}^{(\alpha)}$ values calculated by Ohno [27] (see figure 3-c for $\mathrm{C}_{9}$ ), giving very close results to those of Deleuze $[28,29]$. Ionization cross sections $\sigma(\mathrm{i})$ were calculated within the IAE model [36] assuming all outer valence (respectively inner valence) electrons to be atomic $2 p$ (respectively 2 s) electrons. Note that the separation between outer and inner valence electrons is very clear for all cluster sizes in the work of Ohno and Deleuze (see figure $3 \mathrm{c}$ the case of $n=9$ ). Assuming independent ionizations, internal energy distributions following double ionization (DI) and triple ionization (TI) were calculated by convoluting $\mathrm{f}\left(\mathrm{E}^{\mathrm{SI}}{ }_{\text {ion }}\right)$ with itself once (DI) and twice (TI). Since clusters formed by ionization are multicharged, the coulomb energy had to be added. The coulomb energy was calculated in the model of point charge. We assumed unscreened charges placed at the nuclei of the atomic ionised sites, obtained within the IAE model. Finally internal energy due to electronic excitation associated to ionization, contributing typically $15 \%$ whatever $\mathrm{n}$ and the ionization degree, was added.

For electron capture, no calculations were performed. The energy deposit distribution has been extracted from the statistical analysis of the fragmentation (see section $\mathrm{V}-\mathrm{a}$ ) and was $a$ priori not predictable.

In figure 3 are presented internal energy distributions of $\mathrm{C}_{9}(3-\mathrm{a}), \mathrm{C}_{9}^{+}(3-\mathrm{b}), \mathrm{C}_{9}^{++}(3-\mathrm{d}), \mathrm{C}_{9}^{+++}$ (3-e) and $\mathrm{C}_{9}^{++++}(3-\mathrm{f})$. In order to discuss the fragmentation of these clusters in section $\mathrm{V}$, the internal energy $\mathrm{E}$ (inc) of incident $\mathrm{C}_{\mathrm{n}}^{+}$clusters (before the collision) was added. Mean values of $\mathrm{E}$ (inc) are between 3 and $5 \mathrm{eV}$ depending on $\mathrm{n} \mathrm{[36].} \mathrm{Altogether,} \mathrm{the} \mathrm{size} \mathrm{effect} \mathrm{is} \mathrm{not} \mathrm{large}$ and Figure 3, reported for $n=9$, is typical of energy distributions for all $n$ values. 

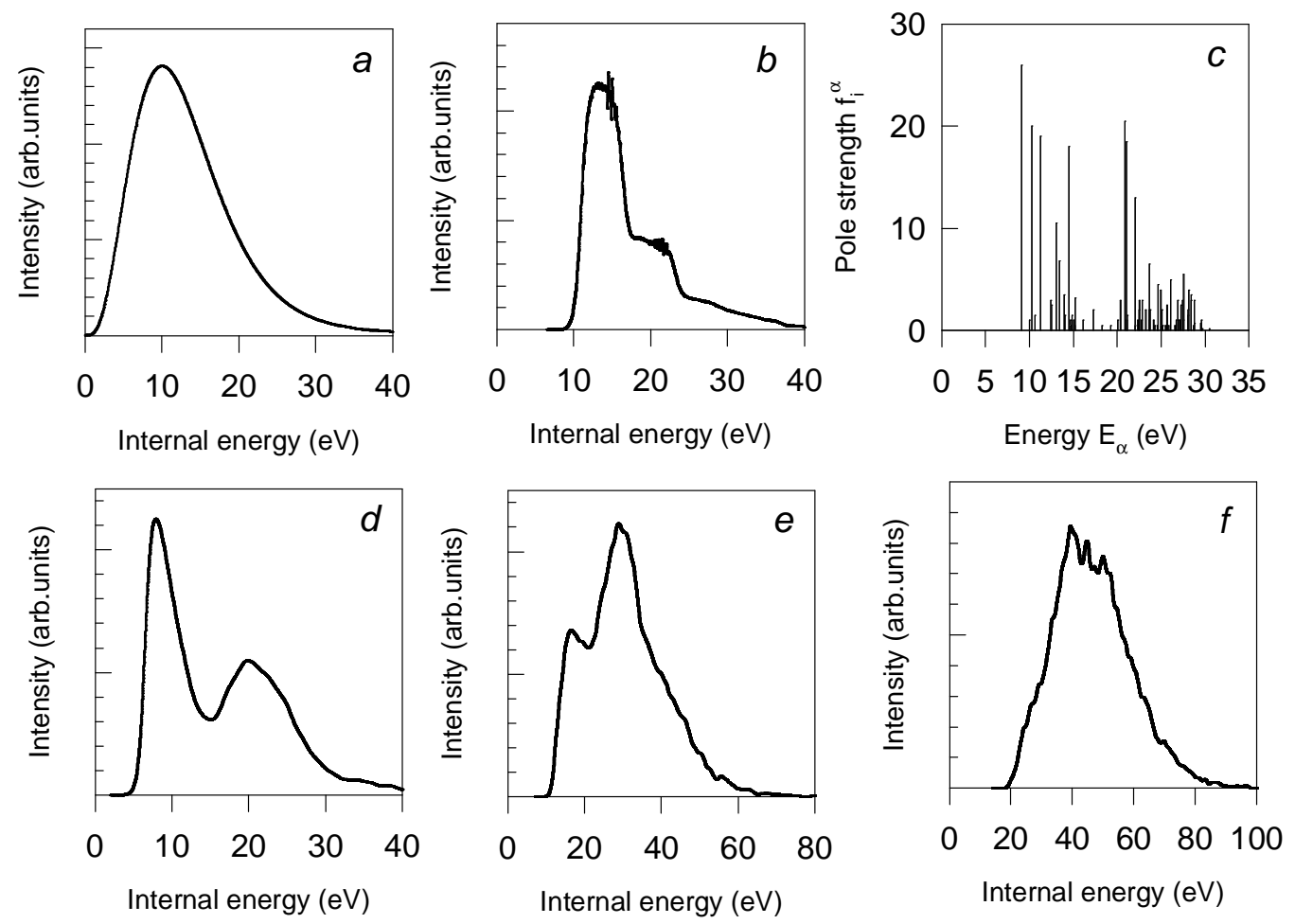

\section{Figure 3:}

\section{V-Fragmentation analysis}

a-Neutral clusters

The complete fragmentation of excited $C_{n}$ clusters has been recorded $(n \leq 10)$ and may be found elsewhere [37]. The analysis of the fragmentation has been conducted within the MMMC formalism and conclusions have also been reported [38, 39]. To summarize, it has been shown that the MMMC model could quite satisfactorily reproduce the numerous experimental branching ratios from $n=5$ ( 7 channels) up to $n=9$ ( 29 channels), basically with the same internal energy distribution for all sizes. This shows that there is an efficient 
electron-phonon coupling in these systems, already for small sizes $(n=5)$ and for quite large internal energies (see figure 3-a).

\section{b-Mono-charged clusters}

All fragmentation channels have been recorded for $\mathrm{C}_{\mathrm{n}}^{+}$clusters $(\mathrm{n}=2-10)$ [37]. For all sizes $(\mathrm{n}>2)$, three-fragments break-up dominate, in accordance with calculated deposited energies (figure 3-b). The MMMC model, applied to $\mathrm{C}_{5}{ }^{+}$, could hardly predict the placement of the charge on the fragments [36]. On the other hand comparison, for two-fragments break-up, of these fragmentation branching ratios with those obtained in photodissociation and CID, shown in figure 4 , indicates that the way energy is deposited plays little role. Since CID branching ratios are very close to the others, it also indicates that dissociation indeed proceeds mainly through the electronic ground state, that means, is statistical. There seems then to be still some theoretical problems to tackle on these systems. 

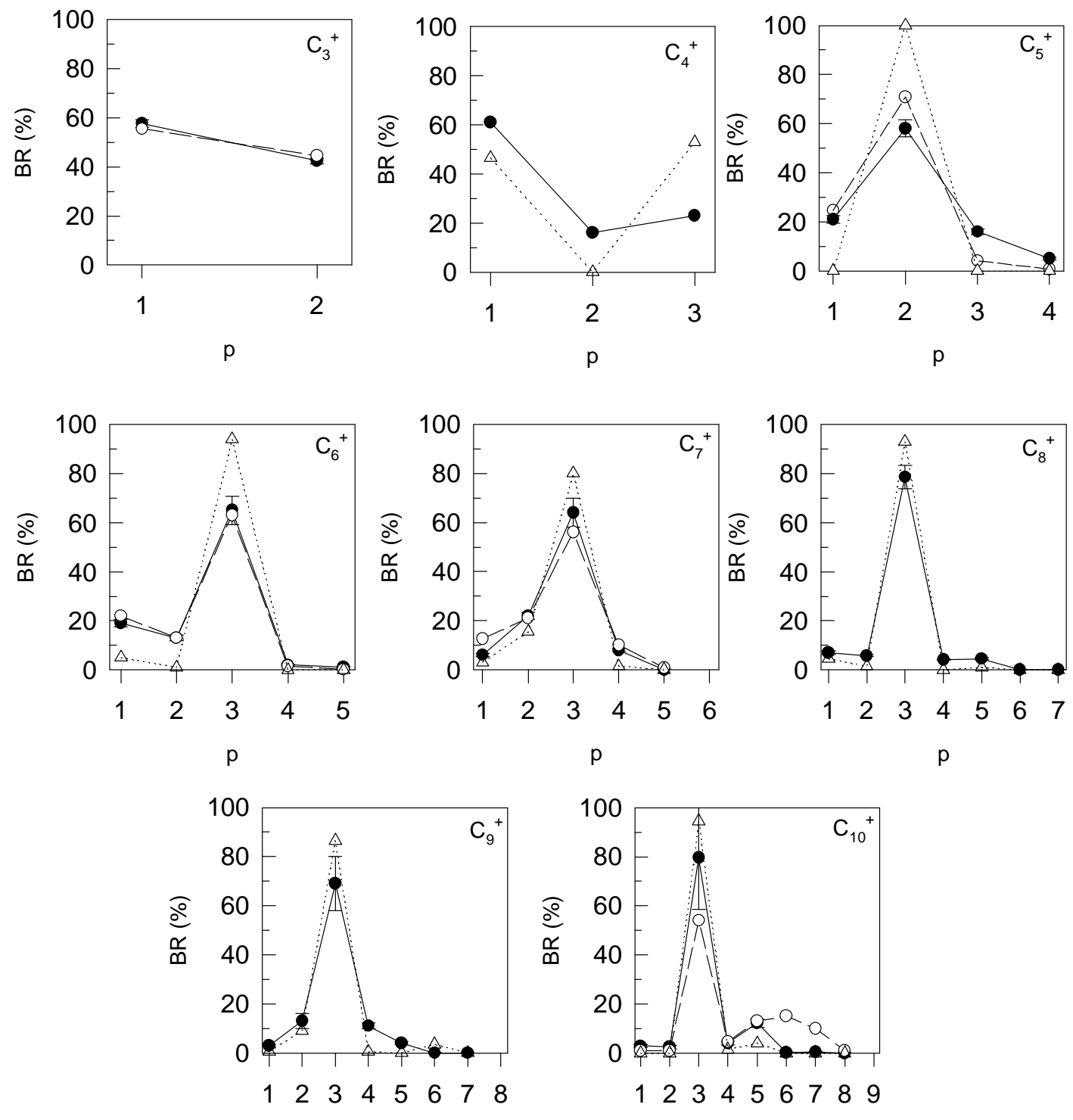

$\mathrm{p}$

$\mathrm{p}$

\section{Figure 4:}

\section{c-Multi-charged clusters}

Multiplicity distributions of $\mathrm{C}_{\mathrm{n}}{ }^{\mathrm{q}+}$ clusters have been found centered around 2, 4/5 and 7 fragments respectively for $\mathrm{q}=2,3,4$. For $\mathrm{n}=9$, this roughly corresponds to mean internal 
energy distributions of figure 3 divided by bond dissociation energies but this correspondence does not hold for all systems and a close examination reveals more subtle energy sharing. Two-fragments branching ratios of $\mathrm{C}_{\mathrm{n}}{ }^{++}$clusters are dominated by fission channels with $\mathrm{C}^{+}$ emission the most probable channel for $\mathrm{n} \leq 7$ and $\mathrm{C}_{3}{ }^{+}$emission the most probable for $\mathrm{n}>7$ as illustrated in figure 6. This behaviour does not follow dissociation energies [22]. Triply charged clusters have very low two- fragments branching ratios (a few \%) and those are dominated by $\mathrm{C}^{+}$emission which is predicted exothermic by theory [23]. The full set of data, which is very large will be published elsewhere. For these systems, specific theoretical fragmentation theories must be developed due to the introduction of long-range coulomb forces.

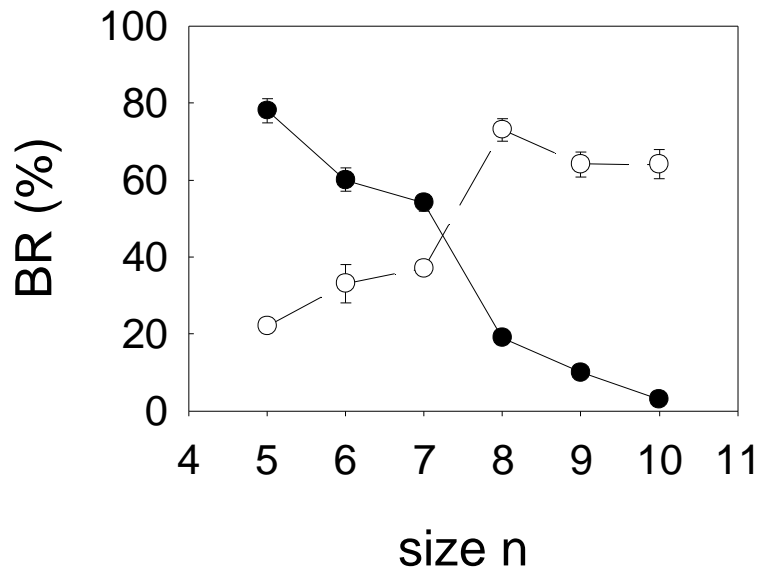

Figure 5 :

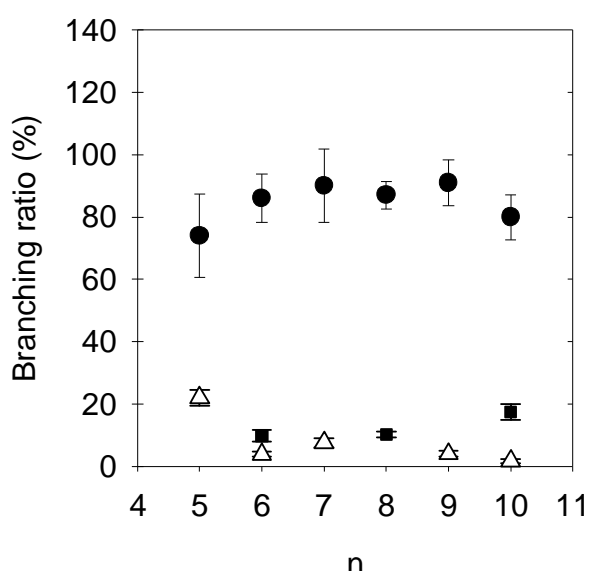

Figure 6 :

As a short conclusion, we showed that fragmentation of electronically excited neutral and monocharged small carbon clusters appeared to be driven by an efficient electron-phonon coupling leading to results in accordance with statistical expectations. The analysis of fragmentation of multicharged species, whose only a small part was shown here, has to be 
done. Other interesting carbon-based molecules are now studied [40] and additional information on fragments momenta planned for the future.

\section{FIGURE CAPTIONS:}

Figure 1: Schematic view of the experimental set-up

Figure 2: Resolving power for the five relaxation channels of excited $\mathrm{C}_{4}$ clusters as a function of the cluster velocity. Figures $2 \mathrm{a}, 2 \mathrm{~b}$ and $2 \mathrm{c}$ refer respectively to $83 \mathrm{keV} / \mathrm{u}, 166 \mathrm{keV} / \mathrm{u}$ and $333 \mathrm{keV} / \mathrm{u}$. Relaxation channels are, from left to right: $\mathrm{C}_{4}, \mathrm{C}_{3} / \mathrm{C}, 2 \mathrm{C}_{2}, \mathrm{C}_{2} / 2 \mathrm{C}$ and $4 \mathrm{C}$.

Figure 3: Internal energy distributions of $\mathrm{C}_{9}(\mathrm{a}), \mathrm{C}_{9}^{+}(\mathrm{b}), \mathrm{C}_{9}{ }^{++}(\mathrm{d}), \mathrm{C}_{9}^{+++}(\mathrm{e}), \mathrm{C}_{9}^{++++}(\mathrm{f})$ after the high velocity collision. In $3-\mathrm{c}$ are reported calculated ionization energies and pole strengths in $\mathrm{C}_{9}[27]$

Figure 4: Fragmentation branching ratios $\mathrm{C}_{\mathrm{n}}{ }^{+}->\mathrm{C}_{\mathrm{p}} / \mathrm{C}_{\mathrm{n}-\mathrm{p}}{ }^{+}$as a function of the neutral fragment size $\mathrm{p}$ and for $\mathrm{n}=3-10$ measured in high velocity collisions (black circles, this work), CID (open circles[8]) and photodissociation (open triangles [4]).

Figure 5: Comparison between $\mathrm{C}^{+} / \mathrm{C}_{\mathrm{n}-1}{ }^{+}$branching ratio (black circle) and $\mathrm{C}_{3}^{+} / \mathrm{C}_{\mathrm{n}-3}{ }^{+}$branching ratio (open circle) in the fragmentation of $\mathrm{C}_{\mathrm{n}}{ }^{++}$clusters as a function of $\mathrm{n}$. Branching ratios are normalised to the total two -fragments dissociation.

Figure 6: Comparison between $\mathrm{C}^{+} / \mathrm{C}_{\mathrm{n}-1}{ }^{++}$branching ratio (black circle), $\mathrm{C}_{2}^{+} / \mathrm{C}_{\mathrm{n}-2}{ }^{++}$branching ratio (open triangle ) and $\mathrm{C}_{3}^{+} / \mathrm{C}_{\mathrm{n}-3}{ }^{++}$branching ratio (black square) in the fragmentation of $\mathrm{C}_{\mathrm{n}}{ }^{++}$clusters as a function of $\mathrm{n}$. Branching ratios are normalised to the total two-fragments dissociation.

\section{REFERENCES:}

1. Van Orden, A. and R. Saykally, Small carbon clusters: Spectroscopy, structure, and energetics. Chemical Reviews, 1998. 98(6): p. 2313-2357.

2. Lifshitz, C., Carbon clusters. Int.J.Mass.Spectr., 2000. 200(1-3): p. 423-442.

3. Bianchetti, M., P.F. Buonsante, F. Ginelli, H.E. Roman, R.A. Broglia, and F. Alasia, Ab-initio study of the electromagnetic response and polarizability of carbon chains. Physics Reports, 2002. 357: p. 459-513.

4. Geusic, M.E., M.F. Jarrold, T.J. McIlrath, L.A. Bloomfield, R.R. Freeman, and W.L. Brown, Photofragmentation of Mass Resolved Carbon Cluster Ions. Zeitschrift Fur Physik D-Atoms Molecules and Clusters, 1986. 3(2-3): p. 309-317.

5. Geusic, M.E., T.J. McIlrath, M.F. Jarrold, L.A. Bloomfield, R.R. Freeman, and W.L. Brown, Photofragmentation of Mass-Resolved Carbon Cluster Ions - Observation of a Magic Neutral Fragment. Journal of Chemical Physics, 1986. 84(4): p. 2421-2422. 
6. Bouyer, R., P. Monchicourt, M. Perdrix, P. Pradel, and F. Roussel, Photodissociation kinetics of Cn+ clusters. Journal of Physics B-Atomic and Molecular Physics, 1997. 30(1): p. 135-145

7. Radi, P.P., T. Bunn, P. Kemper, M. Molchan, and M.T. Bowers, A new method for studying carbon clusters in the gas phase:Observation of size specific neutral fragment loss from metastable reactions of mass selected $C_{n}{ }^{+}, n<60$. J.Chem.Phys., 1988. 88(4): p. 2809-2814.

8. Lifshitz, C., T. Peres, and I. Agranat, Properties of carbon cluster ions $\mathrm{Cn}+$ formed by dissociative ionization. Int.J.Mass. Spectr.Ion.Proc., 1989. 93: p. 149-163.

9. McElvany, S., B. Dunlap, and A. O'Keefe, Ion molecule reactions of carbon cluster ions with $\mathrm{D}_{2}$ and $\mathrm{O}_{2}$. J.Chem.Phys., 1987. 86(2): p. 715-725.

10. Sowa-Resat, M., P. Hintz, and S. Anderson, Dissociation energies for small carbon cluster ions $\left(\mathrm{C}_{2}-C_{19}\right)^{+}$measured by Collision-Induced Dissociation. J.Phys. Chem., 1995. 99: p. 10736-10741.

11. Choi, H., R.T. Bise, A.A. Hoops, D.H. Mordaunt, and D.M. Neumark, Photodissociation of linear carbon clusters $C_{n}(n=4-6)$. Journal of Physical Chemistry A, 2000. 104(10): p. 2025-2032.

12. Heber, O., K. Seiersen, H. Bluhme, A. Svendsen, L.H. Andersen, and L. Maunoury, Dissociative recombination of small carbon cluster cations. Physical Review A, 2006. 73(2): p. 022712.

13. Chen, L., S. Martin, R. Brédy, J. Bernard, and J. Désesquelles, Dynamical fragmentation processes of $C_{60}{ }^{(5+)}$ ions in Ar8+ - C60 collisions. Physical Review A, 2001. 64: p. 031201(R).

14. Deluca, M. and M. Johnson, Photofragmentation of $C_{n}^{-}(4<n<20):$ loss of neutral C3. Chemical Physics Letters, 1988. 152(1): p. 67-70.

15. Lépine, F., A. Allouche, B. Baguenard, C. Bordas, and M. Aubert-Frécon, Computed electron affinity of carbon clusters $C_{n}$ up to $n=20$ and fragmentation energy of anions. J.Phys.Chem.A, 2002. 106: p. 7177-7183.

16. LePadellec, A., F. Rabilloud, D. Pegg, and e. al, Electron-impact detachment and dissociation of $C_{4}^{-}$ions. J.Chem.Phys., 2001. 115(23): p. 10671-10677.

17. Raghavachari, K. and J.S. Binkley, Structure, stability, and fragmentation of small carbon clusters. J.Chem.Phys., 1987. 87(4): p. 2191-2197.

18. Belau, L., S.E. Wheeler, B.W. Ticknor, M. Ahmed, S.R. Leone, W.D. Allen, H.F. Schaefer, and M.A. Duncan, Ionization thresholds of small carbon clusters: Tunable VUV experiments and theory. Journal of the American Chemical Society, 2007. 129(33): p. 10229-10243.

19. Hochlaf, M., C. Nicolas, and L. Poisson, Photoionization of C4 molecular beam:Ab initio calculations. The Journal of Chemical Physics, 2007. 127: p. 014310.

20. Martin, J.M.L., J. El-Yazal, and J.P. François, Structure and relative energetics of $C_{2 n+1}(n=2-7)$ carbon clusters using coupled cluster and hybrid density functional methods. Chemical Physics Letters, 1996. 252: p. 9-18

21. Diaz-Tendero, S., G. Sanchez, P.A. Hervieux, M. Alcami, and F. Martin, Ionization potentials, dissociation energies and statistical fragmentation of neutral and positively charged small carbon clusters. Brazilian Journal of Physics, 2005. 36(2B): p. $529-533$

22. Diaz-Tendero, S., F. Martin, and M. Alcami, Structure, dissociation energies, and harmonic frequencies of small doubly charged carbon clusters $C_{n}^{++}(n=3-9)$. J.Phys.Chem. A, 2002. 106: p. 10782-10789.

23. Sanchez, G., Thesis, unpublished, 2006. 
24. Montagnon, L. and F. Spiegelman, Self-consistent field tight-binding model for neutral and (multi-) charged carbon clusters. The Journal of Chemical Physics, 2007. 127: p. 084111.

25. Haubrich, J., M. Muhlhauser, and S.D. Peyerimhoff, A comparative MRD-CI study of the electronic spectrum of linear and cyclic $C_{8}{ }^{(+)}$clusters. Journal of Molecular Spectroscopy, 2004. 228(1): p. 31-37 and references therein.

26. van Hemert, M.C. and E.F. van Dishoeck, Photodissociation of small carbonaceous molecules of astrophysical interest. Chemical Physics, 2007. 343(2-3): p. 292-302.

27. Ohno, M., V.G. Zakrzewski, J.V. Ortiz, and W. vonNiessen, Theoretical study of the valence ionization energies and electron affinities of linear $C_{2 n+1}(n=1-6)$ clusters. Journal of Chemical Physics, 1997. 106(8): p. 3258-3269.

28. Deleuze, M.S., M.G. Giuffreda, J.P. Francois, and L.S. Cederbaum, Valence oneelectron and shake-up ionization bands of carbon clusters. I. The $C_{n}(n=3,5,7,9)$ chains. Journal of Chemical Physics, 1999. 111(13): p. 5851-5865.

29. Deleuze, M.S., M.G. Giuffreda, J.P. Francois, and L.S. Cederbaum, Valence oneelectron and shake-up ionization bands of carbon clusters. II. The $C_{n}(n=4,6,8,10)$ rings. Journal of Chemical Physics, 2000. 112(12): p. 5325-5338.

30. Radi, P.P., M. Rincon, M.T. Hsu, J. Brodbelt-Lustig, P. Kemper, and M.T. Bowers, structure, reactivity, and energetics of covalently bound carbon cluster ions $C_{5}{ }^{+}$to ${C_{11}}^{+}$: experiment and theory. J.Phys. Chem., 1989. 93(16): p. 6187-6197.

31. Calvo, F. and P. Parneix, Statistical dissociation of small carbon clusters: A phase space theory investigation. Computational Materials Science, 2006. 35(3): p. 198-202.

32. Diaz-Tendero, S., P.A. Hervieux, M. Alcami, and F. Martin, Statistical fragmentation of small neutral carbon clusters. Physical Review A, 2005. 71(3): p. 033202.

33. Chabot, M., S. Della Negra, L. Lavergne, G. Martinet, K. Wohrer-Beroff, R. Sellem, R. Daniel, J. Le Bris, G. Lalu, D. Gardes, J.A. Scarpaci, P. Desesquelle, and V. Lima, Shape analysis of current pulses delivered by semiconductor detectors: A new tool for fragmentation studies of high velocity atomic clusters and molecules. Nuclear Instruments \& Methods in Physics Research Section B-Beam Interactions with Materials and Atoms, 2002. 197(1-2): p. 155-164.

34. Chabot, M., F. Mezdari, G. Martinet, K. Wohrer-Béroff, S. DellaNegra, P. Désesquelles, H. Hamrita, A. LePadellec, and L. Montagnon, Fragmentation of small carbon clusters. Proceedings of the XXIV International conference on Photonic, Electronic and Atomic collisions, 2006: p. 607-614.

35. Krummacher, S., V. Schmidt, F. Wuilleumier, J.M. Bizau, and D. Ederer, Inner-Shell Photoionisation in Molecules - the Carbon-Monoxide Case. Journal of Physics BAtomic Molecular and Optical Physics, 1983. 16(10): p. 1733-1747.

36. Mezdari, F., Fragmentation d'agrégats de carbone (multi)chargés formés par ionisation et excitation en collision de haute vitesse. PHD thesis, Université Pierre et Marie Curie Paris VI (unpublished), 2005.

37. Chabot, M., G. Martinet, F. Mezdari, S. Diaz-Tendero, K. Beroff-Wohrer, P. Desesquelles, S. Della-Negra, H. Hamrita, A. Le Padellec, T. Tuna, L. Montagnon, M. Barat, M. Simon, and I. Ismail, Charge transfer in high velocity ${C_{n}}^{+}+$He collisions. Journal of Physics B-Atomic Molecular and Optical Physics, 2006. 39(11): p. 25932603.

38. Martinet, G., S. Diaz-Tendero, M. Chabot, K. Wohrer, S. Della Negra, F. Mezdari, H. Hamrita, P. Desesquelles, A. Le Padellec, D. Gardes, L. Lavergne, G. Lalu, X. Grave, J.F. Clavelin, P.A. Hervieux, M. Alcami, and F. Martin, Fragmentation of highly excited small neutral carbon clusters. Physical Review Letters, 2004. 93(6): p. 063401. 
39. Diaz-Tendero, S., G. Sanchez, M. Alcami, F. Martin, P.A. Hervieux, M. Chabot, G. Martinet, P. Desesquelles, F. Mezdari, K. Wohrer-Beroff, S. Della Negra, H. Hamrita, A. Le Padellec, and L. Montagnon, Fragmentation of small neutral carbon clusters. International Journal of Mass Spectrometry, 2006. 252(2): p. 126-132.

40. Tuna, T., M. Chabot, T. Pino, J. Désesquelles, A. LePadellec, G. Martinet, M. Barat, B. Lucas, F. Mezdari, L. Montagnon, N.T. Van-Oanh, L. Lavergne, A. Lachaize, Y. Carpentier, and $\mathrm{K}$. Béroff, Fragmentation branching ratios of highly excited hydrocarbon molecules $C_{n} H$ and their cations $C_{n} H^{+}(n \leq 4)$. The Journal of Chemical Physics, 2008. 128: p. 124312. 